\title{
Legal regulation of the safety of autonomous ships: environmental challenges and approaches
}

\author{
El Houcine Chougrani ${ }^{1}$, Naser Abdel Raheem Al Ali ${ }^{2,}$, and Vladimir Chebotarev ${ }^{3}$ \\ ${ }^{1}$ University Kadi Ayyad, Marrakesh, Morocco \\ ${ }^{2}$ Russian University of Transport, Obraztsova str. 9-9, 127994 Moscow, Russia
}

\begin{abstract}
This study aims to explain the difficulty of the absence of legal regulation of the safety of autonomous and the effects of automation systems (ships in this study) on the human (jobs, skills, human behavior) and nature (pollution, loss of biodiversity, damage, etc). So the human should introduce a novel manner of thinking with the effect of the ethical and moral principle of automation. Our contribution will; focuses on the problem that how to conciliate between the huge positive technology evolution and the negative impact on the human and nature. This paper addresses the need to renew and positioning research in light of this contending.
\end{abstract}

\section{Introduction}

There are many unresolved issues in maritime law, such as the shift to automation human vision, at the age of the Fourth Industrial Revolution and modern scientific progress. It is the age of globalization and virtual recognition. Furthermore, the maker's decision thinks about the safety of the market and enhancing the firm's capital. So, we should introduce a novel manner of thinking to formulate and elaborate actions to define a specific regulation or regime instrument about the digital in the marine challenges to face a new marine constraint as the marine resources and coastal ecosystems save.

The rebalancing of power among actors in international affairs was accelerated by the information revolution [15] processes. This dysfunction of balance is apparent and evident, especially in the maritime industry sphere with huge exploitation of marine biodiversity and marine pollution.

International shipping transports more than 80 percent of global trade to peoples and communities all over the world. Shipping is the most efficient and cost-effective method of international transportation for most goods; it provides a dependable, low-cost means of transporting goods globally, facilitating commerce and helping to create prosperity among nations and peoples [3].

In this framework, the autonomous vessel [16] (unmanned vessel, autonomous ship [2]) finds a way to replace and change human action. It is the effect of the innovation and efficiency of the human dream. It may be the logical thing to regulate [8] the autonomous

*Corresponding author: drnasernimer@ui-miit.ru 
vessel [7]. Besides, it is unexpected to understand the absence of international instruments to safe the autonomous ships with his correlation to the marine environment. In addition, it is very difficult to study all ships types (Commercial, Passenger, and Defense), all levels of autonomous (semi-autonomous and fully-autonomous), Component (Hardware and Software), and fuel types (carbon-neutral fuels, Electric and Heavy Fuel Oil/ Marine Engine Fuel), etc.

Autonomous technology is gradually reshaping the maritime industry bringing benefits such as increased operational efficiency, human error reduction, emission reduction, increased safety, and operational cost reduction. Regulation, engineering, and culture all present challenges as significant as the development of technology itself [5]. It is the logic of technology evolution in all levels and fields (economic, trade, investment, etc).

\section{Materials and methods}

This paper aims to analyze and explain the effects of the absence of effective international regulations to the autonomous ships by explaining the impacts and influences of automation systems on the human (jobs, skills, behavior, etc) and nature (pollution, loss of biodiversity, damage, etc).

\section{Results and discussion}

Navigation conditions have become complicated and difficult for the human direction. It is important and a central key to keep saving the human elements and the shipping safety of the world's navigation.

Most accidents at sea are a result of human error. This is why if human operators are replaced by sophisticated sensors and computer systems, autonomous vessels should/could make shipping safer [9]. But, the unmanned operation is not suited for all types of ships we will still have seafarers at sea in the future [10]. In all areas of the trend for ships, intelligence is towards more smart and automated systems and the role of the crew is in supervising the operation [11]. But, these tendencies evolutions can be a negative approach if we cannot control it by legal, ethical norms or moral principles.

Recent advances [14] in geolocation technology have developed self-reporting maritime systems such as automatic identification systems (AIS) for maritime safety. The problem is not a technical aspect, but the huge constraints are the ambiguous status of an unmanned vessel in international rules or regulations norms particularly in the International Maritime Organization (IMO) system.

Autonomy technology is progressing faster and more rapidly moving, express advances in robotics than international law regulation characterizing by its soft vision (unlikely to be in force). Challenging policymakers to adopt a new instrument and formal texts in the era of digital conflict, in that sense, we should be working together under an umbrella of the United Nations system to elaborate hard rules. Also, the challenges will be to find a new mechanism to interact with the transport profit, the effective regulation of maritime security, and the environmental marine safety.

A larger discussion and debate of the ethical and morals issues of unmanned systems (Autonomous Weapons) can make our survival life complicated due to our interaction and reaction with technology advanced in various and multitudes fields. Ethical conduct can be made by societies to improve a positive behavior to use unmanned systems. But the reality is noted badly with the risk of society and the influence of technology and the postmodern negative effect. Perhaps is the organized irresponsibility by the global risks in our societies. 
There are several ethical dilemmas specific to these technologies under the distinctive character of the war at sea [17]. In the field of liability, there are more difficult.

According to Safety of Life at Sea Conventions (SOLAS) Chapter V, Regulation 19 [4]. 2.4 All ships of 300 gross tonnages and upwards engaged on international voyages and cargo ships of 500 gross tonnages and upwards not engaged on international voyages and passenger ships irrespective of size shall be fitted with an Automatic Identification System (AIS).

In the recent evolution, The Maritime Safety Committee (MSC) endorsed a framework for a regulatory scoping exercise, as work in progress, including preliminary definitions of Maritime Autonomous Surface Ships (MASS) and degrees of autonomy, as well as a methodology for conducting the exercise and a plan of work [1].

While the IMO has a long way to go to create rules on the use of unmanned autonomous cargo vessels on the high seas, it has created guidelines of test areas as well as a 4 stage definition of autonomy [1].

- $\quad$ Degree one: Ship with automated processes and decision support: Seafarers are on board to operate and control shipboard systems and functions. Some operations may be automated and at times be unsupervised but with seafarers on board ready to take control.

- Degree two: Remotely controlled ship with seafarers on board: The ship is controlled and operated from another location. Seafarers are available onboard to take control and to operate the shipboard systems and functions.

- Degree three: Remotely controlled ship without seafarers on board: The ship is controlled and operated from another location. There are no seafarers on board.

- Degree four: Fully autonomous ship: The operating system of the ship can make decisions and determine actions by itself.

The promotion of sustainable shipping and sustainable maritime development is one of the major priorities of IMO in the coming years [3]. Indeed, most of the elements of the 2030 Agenda SDGs [13] will only be realized with a sustainable transport sector supporting world trade and facilitating the global economy [3].

Regulation must be flexible enough to address the risks of a highly varied industry to support safety innovation and business and environmental sustainability [12]. It is a way to improve our comprehension of this evolution in the context of era globalization.

Opportunities in the marine sector are [18] shared capacity, big data analytic, Smart Vessels, and automated ports. But, to continue with this evolution, we have many difficulties with skill Autonomy technology, for example, how to reduce the cost of shipping cargo and how to decrease $\mathrm{CO}_{2}$. It is the verse between trade operations (capital accumulation) and environmental protection (liability and responsibility for marine damage and oil pollution [4]. Efforts should be made by the IMO especially under Legal Committee to find and guidelines and effective instruments to balance this contending equation.

The IMO's current long list of conventions, regulations, guidelines, and other instruments have been written over the decades to ensure the safety of international shipping. The new tendency and mutations of rapid robotics management should take into concern by the law and norms regulations. We know that the rules are a social background so we must change the paradigm to control this robotics evolution and to adapt to the radical transformations on technology mutations. It is the capability of human vision that can manipulate it with his dream but without suffering the nature and human. As noted above, it is a very serious obstacle that conditions the enforcement of international maritime law especially to assure of marine ecosystems sustain.

The scope of the autonomous ships requires revitalized global actors in the domain of maritime and all stakeholders (organizations, companies, and other industry bodies) and maybe implements the approach to de-carbonization. Creating a specific mechanism for 
automation is a very complicated effort that we can guarantee the effective use for autonomous ships without damage to humans and nature.

\section{Conclusion}

It seems that there is a huge gap between the human evolution dream and the impact of automation on human survival and nature protection. More importantly, automation rebalances the power between all stakeholders and actors in international law. The navigation conditions become more difficult and more complicated; this affects ethics in the risk society era and influences the postmodern life.

The IMO should take into account the new tendencies and mutations technology in the sphere of marine navigation. This can be a solution to save the environment and guarantee survival life and ethical sharing by all nations and peoples. It is a challenging complex task and intersecting subject within social science, but surely it will be a part of the solution. One of the most important challenge facing policymakers and all stakeholders is to develop and enhance a specific approach to find equilibrium between automation evolution and the impact on the human situation and natural deterioration.

\section{References}

1. C. Eason, IMO scoping study on autonomous ships unlikely to result in new regulations until the 2030 's despite member states seeking to be technology market leaders (2021) https://fathom.world

2. Future ready: advancing from automated to autonomous shipping. American Bureau of Shipping (ABS) (2021) https://ww2.eagle.org

3. Introduction to International Maritime Organization. See the web site IMO (2021) https://www.imo.org

4. Conventions (SOLAS) Chapter V regulations (2021) https://www.navcen.uscg.gov

5. American Bureau of Shipping (ABS): Future Ready: Advancing From Automated To Autonomous Shipping (2021) https://ww2.eagle.org

6. Australian Government. Australian Maritime Safety Authority. Autonomous shipping from a regulatory perspective (2018) https://www.iala-aism.org

7. R. Rylander, Y. Man, Autonomous safety on vessels. An international overview and trends within the transport sector, 2 (Lighthouse Reports, 2016) https://www.lighthouse.nu

8. Cambridge Advanced Learner's Dictionary, 1197 (Cambridge University Press, 2008)

9. D. Cunningham (SEA Europe/ Waterborne Technology Platform. MUNIN Workshop at SMM): Waterborne TP SRA: The Autonomous Ship (2014) http://www.unmannedship.org

10. E. Jokioinen, Towards Remote Controlled Ships 2014. MUNIN Workshop Professional Insight on Unmanned Ships Norshipping (2014) http://www.unmannedship.org

11. E. Jokioinen, Towards Remote Controlled Ships. 2014 Rolls-Royce plc. Rolls Royce Marine. 10.9.2014 - MUNIN Workshop at SMM, http://www.unmanned-ship.org

12. N. Lemon, Autonomous shipping from a regulatory perspective Australian Government. Australian Maritime Safety Authority (AMSA) (2018) https://www.ialaaism.org 
13. GA (United Nations) 70/1. Transforming our world: the 2030 Agenda for Sustainable Development. Resolution adopted by the General Assembly on 25 September 2015: Goal 14. Conserve and sustainably use the oceans, seas, and marine resources for sustainable development.

14. He Huang, Kaiyue Qiu, Myeong-Hun Jeong, Seung Bae Jeon, and Woo Pyeong Lee. Detecting Anomalous Vessel Dynamics with Functional Data Analysis, Journal of Coastal Research, 91, 406 (2019)

15. J. Baylis, S. Smith. The Globalization of World Politics. An introduction to international relations (Oxford University Press, 2005)

16. L. Lucchini, M. Voelckel, Droit de la mer, 2(2) (Paris: Ed Pedone, 1996)

17. R. Sparrow, G. Lucas, Naval War College Review, 69(4) (2016)

18. Timo Koponen Vice President, Processing Solutions, Wärtsilä Marine Solutions, 3 (2010) https://wwwcdn.imo.org 